\title{
Arsenic and Fluoride Removal by Iron Oxide and Iron Oxide/Alumina Nanocomposites: A Comparison
}

\author{
Prathna TC ${ }^{1}$, Saroj K Sharma ${ }^{1}$, Maria Kennedy ${ }^{1,2}$ \\ ${ }^{1}$ Environmental Engineering and Water Technology Department, UNESCO-IHE Institute for Water Education \\ 2601 DA, Delft, The Netherlands \\ p.thanjavur@unesco-ihe.org; s.sharma@unesco-ihe.org \\ ${ }^{2}$ Faculty of Civil Engineering, Delft University of Technology \\ Stevinweg 1, 2628 CN, Delft, The Netherlands \\ m.kennedy@unesco-ihe.org
}

\begin{abstract}
The study provides a comparative analysis of As (III), As (V) and F removal by iron oxide nanoparticles and iron oxide/alumina nanocomposites. The nanoparticles were characterized by particle size, zeta potential and Scanning Electron Microscopic analysis which showed spherical iron oxide nanoparticles around $\sim 200 \mathrm{~nm}$ and nanocomposites around $\sim 300 \mathrm{~nm}$. Batch sorption studies carried out at varying initial concentrations of As and $\mathrm{F}$ revealed an enhanced $\mathrm{F}$ and As sorption capacity for the nanocomposites. The sorption isotherm showed that the data for As (III), As (V) and F fitted best to Freundlich isotherm for both the type of nanoparticles. The maximum sorption capacity of the iron oxide nanoparticles for As (III) and As (V) at $\mathrm{pH} 7 \mathrm{were} 909 \mu \mathrm{g} / \mathrm{g}$ and $3333 \mu \mathrm{g} / \mathrm{g}$ while the comparative qm values for the nanocomposites were $1000 \mu \mathrm{g} / \mathrm{g}$ and $2500 \mu \mathrm{g} / \mathrm{g}$ respectively. The maximum $\mathrm{F}$ sorption capacity of iron oxide nanoparticles was $1.47 \mathrm{mg} / \mathrm{g}$ while it was $4.82 \mathrm{mg} / \mathrm{g}$ for the nanocomposites. The preliminary results of the study showed that the nanocomposites can be promising adsorbents for both As and F removal in small scale water systems.
\end{abstract}

Keywords: iron oxide, alumina, nanoparticles, arsenic, fluoride

\section{Introduction}

Contamination of drinking water sources continues to pose a challenge in almost all parts of the world and thus one of the Sustainable Development Goals (SDG 6) of the United Nations is to ensure universal access of safe drinking water to all by 2030 [1]. Among the various inorganic contaminants in water, arsenic and fluoride have been determined to be the contaminants most detrimental to human health [2]. Studies have indicated the co-existence of both arsenic and fluoride in many aquifers and hence there is an urgent need to develop techniques to simultaneously remove both arsenic and fluoride $[3,4]$. The major challenge is to design and optimize a material which is safe and easy to use at both household and small community levels which would go a long way in reducing treatment cost.

Various materials have been tested as possible adsorbents for the removal of arsenic and fluoride from water, like alumina, iron based oxides, rare metal oxides, activated carbon, bone char to name a few $[5,6]$. In recent decades, there has been increased interest in the application of nanomaterials in environmental applications such as in contaminant removal or toxicity mitigation [7]. Iron oxide based materials are known for their affinity towards arsenic and fluoride removal while alumina is known for its efficient fluoride removal potential [8].

Therefore, in the present study, an attempt was made to compare the feasibility of iron oxide nanoparticles and iron oxide/alumina nanocomposites as adsorbents for removal of arsenic and fluoride. In order to achieve this, iron oxide nanoparticles and iron oxide/alumina nanocomposites were synthesized, characterized and their arsenic and fluoride removal efficiency studied. 


\section{Materials and Methods}

\subsection{Synthesis of Iron Oxide Nanoparticles}

The method of Zhang et al was followed with modifications [9]. Briefly, $0.279 \mathrm{~g}$ of $\mathrm{FeCl}_{3} \cdot 6 \mathrm{H}_{2} \mathrm{O}$ and $1.395 \mathrm{~g}$ of $\mathrm{FeCl}_{2} \cdot 4 \mathrm{H}_{2} \mathrm{O}$ were dissolved in $100 \mathrm{~mL}$ ethanol to which $14.7 \mathrm{M} \mathrm{NH}_{3}$ was added dropwise until $\mathrm{pH}$ reached 9. The flask was placed at $50^{\circ} \mathrm{C}$ for 3 hours and the contents were centrifuged and the pellet dried [10].

\subsection{Synthesis of Iron Oxide/Alumina Nanocomposites}

The method of Amirsalari et al [11] was followed with modifications. Briefly, $3.75 \mathrm{~g}$ of $\mathrm{Al}\left(\mathrm{NO}_{3}\right)_{3} .9 \mathrm{H}_{2} \mathrm{O}$ was dissolved in $100 \mathrm{ml}$ of deionized water and the solution was heated to $60{ }^{\circ} \mathrm{C}$. The solution was then precipitated by the addition of $\mathrm{NH}_{3}$ solution. To the obtained aluminium hydroxide gel, $0.05 \mathrm{~g}$ of prepared iron oxide nanoparticles were added and stirring was continued for $12 \mathrm{~h}$. The contents were then centrifuged and the pellet dried and calcined at $550{ }^{\circ} \mathrm{C} / 3 \mathrm{~h}$.

\subsection{Physico Chemical Characterization}

Particle size analyser was used to determine the average particle size while zeta potential studies were used to study the point of zero charge. EDAX analysis was performed to determine the elemental composition of the samples. Adsorption isotherm studies were performed at $\mathrm{pH} 7$ at different initial concentrations for both arsenic and fluoride. Langmuir and Freundlich isotherms were used to fit the adsorption data from equilibrium experiments.

\section{Results and Discussion}

Spherical nanoparticles of around $192 \pm 5.96 \mathrm{~nm}$ and $273 \pm 19.49 \mathrm{~nm}$ in diameter were observed for iron oxide nanoparticles and the iron oxide/alumina nanocomposites respectively. The surface charge of an adsorbent is determined by the $\mathrm{pH}$ of the solution. Hence, the efficacy of an adsorbent in adsorbing contaminants will be affected by the $\mathrm{pH}$ of the solution [12]. Zeta potential studies revealed that point of zero charge was $\sim \mathrm{pH} 9$ and $\sim \mathrm{pH} 6.5$ for the nanoparticles and nanocomposites respectively (Figure 1). EDAX analysis confirmed the presence of Fe, $\mathrm{O}$ peaks for the iron oxide nanoparticles and in addition Al peaks for the alumina/iron oxide nanocomposites.

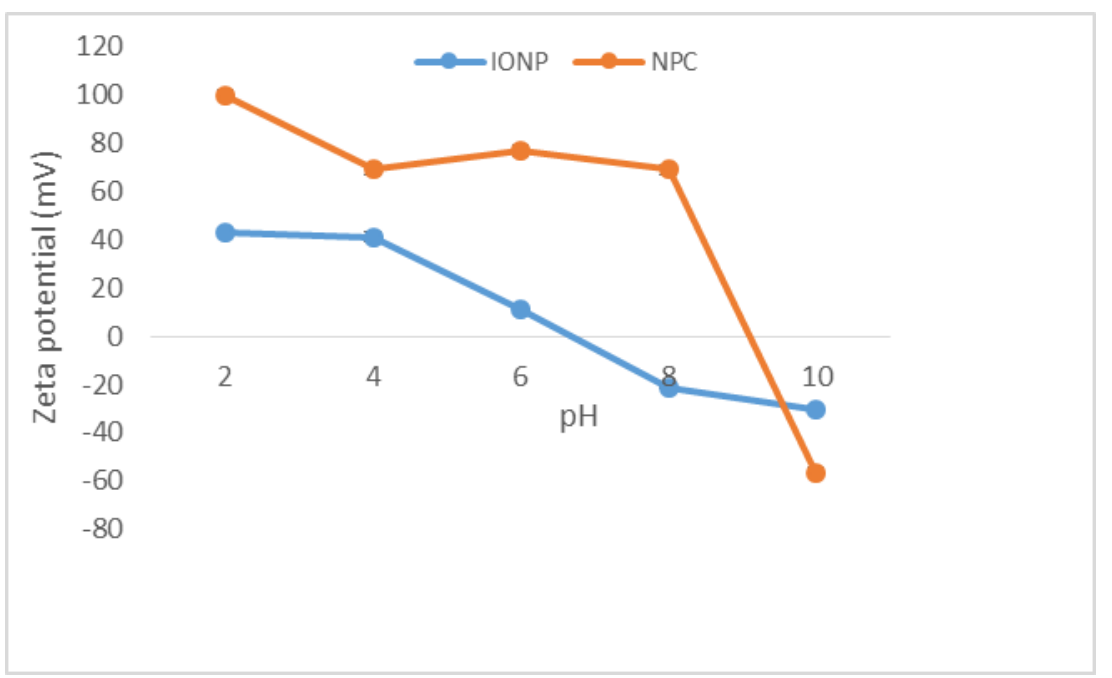

Fig. 1: Point of zero charge of iron oxide nanoparticles (IONP) and iron oxide/alumina nanocomposites (NPC).

Sorption studies were performed at varying initial concentrations of fluoride and arsenic. In all cases, the adsorption capacity increased with increase in initial concentration of F and As (III), As (V) for both the iron oxide nanoparticles and the nanocomposites. An enhanced F sorption capacity was observed for the nanocomposites as compared to the iron oxide nanoparticles as was the case with As (III).

In order to further determine the mode of adsorption of the adsorbent, isotherm studies were carried out and the data was analysed. The data in all cases fitted well with the Freundlich isotherm. The $\mathrm{k}_{\mathrm{f}}$ values of the nanocomposites were significantly higher for As (V) $(145.75 \mu \mathrm{g} / \mathrm{g})$ as compared to iron oxide nanoparticles $(46.88 \mu \mathrm{g} / \mathrm{g})$. The $\mathrm{q}_{\mathrm{m}}$ values were 
nearly similar for As (III) for both the iron oxide nanoparticles and the nanocomposites. However, there was a significant increase in the $\mathrm{q}_{\mathrm{m}}$ values of the nanocomposites towards $\mathrm{F}(4.82 \mathrm{mg} / \mathrm{g})$ as compared to iron oxide nanoparticles $(1.47 \mathrm{mg} / \mathrm{g})$. The $\mathrm{q}_{\mathrm{m}}$ and $\mathrm{k}_{\mathrm{f}}$ values of the adsorbents towards As and $\mathrm{F}$ are tabulated in Table 1 .

Table 1: Summary of parameters obtained from Freundlich and Langmuir isotherms for iron oxide nanoparticles and nanocomposites towards As (III), As (V) and F adsorption.

\begin{tabular}{|c|c|c|c|c|}
\hline & \multicolumn{2}{|c|}{ Freundlich isotherm } & \multicolumn{2}{|c|}{ Langmuir isotherm } \\
\hline & $k_{f}(\mu g / g)$ & $\mathbf{R}^{2}$ & $q_{m}(\mu g / g)$ & $\mathbf{R}^{2}$ \\
\hline & \multicolumn{4}{|c|}{ As (III) } \\
\hline $\begin{array}{l}\text { Iron oxide } \\
\text { nanoparticles }\end{array}$ & 25.35 & 0.93 & 909 & 0.68 \\
\hline \multirow[t]{2}{*}{\begin{tabular}{l}
\multicolumn{1}{c}{ Iron } \\
oxide/alumina \\
nanocomposites
\end{tabular}} & 34.89 & 0.91 & 1000 & 0.83 \\
\hline & \multicolumn{4}{|c|}{ As (V) } \\
\hline $\begin{array}{l}\text { Iron oxide } \\
\text { nanoparticles }\end{array}$ & 46.88 & 0.98 & 3333 & 0.98 \\
\hline \multirow{3}{*}{\begin{tabular}{c}
\multicolumn{1}{c}{ Iron } \\
oxide/alumina \\
nanocomposites
\end{tabular}} & 145.75 & 0.86 & 2500 & 0.61 \\
\hline & \multicolumn{4}{|c|}{$\mathrm{F}$} \\
\hline & $\mathbf{k}_{\mathbf{f}}(\mathbf{m g} / \mathbf{g})$ & $\mathbf{R}^{2}$ & $q_{m}(\mathrm{mg} / \mathrm{g})$ & $\mathbf{R}^{2}$ \\
\hline $\begin{array}{l}\text { Iron oxide } \\
\text { nanoparticles }\end{array}$ & 0.78 & 0.64 & 1.47 & 0.48 \\
\hline \begin{tabular}{l}
\multicolumn{1}{c}{ Iron } \\
oxide/alumina \\
nanocomposites
\end{tabular} & 1.19 & 0.92 & 4.82 & 0.86 \\
\hline
\end{tabular}

The results suggest that the synthesized iron oxide/alumina nanocomposites can be promising adsorbents for both arsenic and fluoride and maybe further studied as adsorbents for small scale water treatment systems.

\section{Conclusion}

The iron oxide/alumina nanocomposites possessed optimum sorption capacity towards both arsenic and fluoride as compared to iron oxide nanoparticles. The iron oxide nanoparticles had a higher qm value towards As (V) but had poor sorption capacity towards F as compared to the nanocomposites. Further detailed studies into the adsorption behaviour of iron oxide/alumina nanocomposites would be required in designing the nanocomposites as adsorbents for small scale water treatment systems for the simultaneous removal of fluoride and arsenic. One of the main challenges would be to determine an effective way to use the nanocomposites in the powdered form more effectively for point of use water treatment systems.

\section{Acknowledgements}

This study was carried out as a part of EU COFUND programme- Experienced Water Post Doc Fellowship (Grant Agreement no. 606838. The authors acknowledge the support of UNESCO-IHE lab staff in conducting various analysis.

\section{References}

[1] United Nations, Transforming our world: the 2030 Agenda for Sustainable Development, A/RES/70/1, 2015.

[2] T. Thompson, J. Fawell, S. Kunikane, D. Jackson, S. Appleyard, P. Callan, J. Bartram and P. Kingston, In: Chemical Safety of Drinking Water: Assessing Priorities for Risk Management. World Health Organization, Geneva, VII, pp. 142, 2007.

[3] M. A. Armienta and N. Segovia, "Arsenic and fluoride in the groundwater of Mexico," Environ. Geochem. Health, vol. 30, no. 4, pp. 345-353, 2008. 
[4] C. Warren, W.G. Burgess and M.G. Garcia, "Hydrochemical associations and depth profiles of arsenic and fluoride in Quaternary loess aquifers of Northern Argentina," Mineralogical Magazine, vol. 69, no. 5, pp. 877-886, 2005.

[5] A. Salifu, B. Petrusevski, K. Ghebremichael, L. Modestus, R. Buamah, C. Aubry and G.L. Amy, "Aluminium (hydr)oxide coated pumice for fluoride removal from drinking water: Synthesis, equilibrium kinetics and mechanism," Chem. Eng. J., vol. 228, pp. 63-74, 2013.

[6] W. Li, C. Y. Cao, L. Y. Wu, M. F. Ge and W. G. Song, "Superb fluoride and arsenic removal performance of highly ordered mesoporous aluminas," J. Hazard. Mater., vol. 198, pp. 143-150, 2011.

[7] P. G. Tratnyek and R. L. Johnson, "Nanotechnologies for environmental cleanup," Nano Today, vol. 1, pp. 44-48, 2006.

[8] J. Qiao, Z. Cui, Y. Sun, Q. Hu and X. Guan, "Simultaneous removal of arsenate and fluoride from water by Al-Fe (hydr) oxides," Front. Environ. Sci. Eng., vol. 8, no. 2, pp. 169-179, 2014.

[9] C. Zhang, L. Chen, T. J. Wang, C. L. Su and Y. Jin, "Synthesis and properties of a magnetic core-shell composite nano-adsorbent for fluoride removal from drinking water," Appl. Surf. Sci., vol. 317, pp. 552-559, 2014.

[10] T. C. Prathna. S. K. Sharma and M. Kennedy, "Development of iron oxide nanoparticle adsorbents for arsenic and fluoride removal," Desalin. Water Treat., 2017.

[11] A. Amirsalari and S. F. Shayesteh, "Effects of $\mathrm{pH}$ and calcination temperature on structural and optical properties of alumina nanoparticles," Superlattices and Microstructures, vol. 82, pp. 507-524, 2015.

[12] W. Li, C. Y. Cao, L. Y. Wu, M. F. Ge and W. G. Song, "Superb fluoride and arsenic removal performance of highly ordered mesoporous aluminas," J. Hazard. Mater., vol. 198, pp. 143-150, 2011. 